\title{
Impact of the Gravity Field and Steady-State Ocean Circulation Explorer (GOCE) mission on ocean circulation estimates. Volume fluxes in a climatological inverse model of the Atlantic
}

\author{
Pascal LeGrand ${ }^{1}$ \\ Laboratoire de Physique des Oceans, IFREMER, Plouzane, France
}

\begin{abstract}
The Gravity Field and Steady-State Ocean Circulation Explorer (GOCE) mission, by providing a precise estimate of the marine geoid height, will allow the determination of absolute geostrophic velocities at the surface of the ocean with unprecedented accuracy. The resulting impact on oceanic flux estimates is quantified within a climatological inverse model of the Atlantic in terms of reduction of uncertainties in volume transports. These uncertainty reductions are obtained by replacing the error spectrum of present-day geoid models by the error spectrum expected for the GOCE mission. The impact is large in the Circumpolar Current, with relative uncertainty reductions reaching $50 \%$ in the upper layers of the ocean, and $40 \%$ in the whole water column. It is also large in regions of sharp oceanic fronts like the Gulf Stream or the Brazil Current, with uncertainty reductions reaching $60 \%$ in the upper layers of the ocean. The reduction in transport uncertainties is large enough in absolute terms to have a significant impact on estimates of important climate processes like the rate of overturning in the Atlantic or the exchange of water between the Circumpolar Current and the South Atlantic. The impact of the Gravity Recovery and Climate Experiment (GRACE) mission, estimated within the same inverse model, is on average less than half the impact of GOCE because of the lower precision of this mission at small spatial scales. The fact that uncertainties in the baroclinic component of the velocity field limit the impact of GOCE at depths points to the need for precise in situ observations to complement gravity and altimetric observations.
\end{abstract}

\section{Introduction}

One of the goals of the Gravity Field and Steady-State Ocean Circulation Explorer (GOCE) mission, scheduled for launch in 2005 by the European Space Agency, is to provide unprecedented, accurate measurements of the gravity field over the ocean [European Space Agency, 1999]. These measurements will yield a precise estimate of the marine geoid height, which in combination with altimetric observations of the sea surface height, will allow a precise estimate of the ocean dynamic topography and of the associated surface geostrophic currents. Knowledge of the absolute value of these currents, which is difficult to obtain from hydrographic measurements alone, will in tum provide improved estimates of oceanic fluxes. The objective of the present work is to quantify these improvements.

This study is the first in a series of four. It investigates the impact of GOCE on volume transport uncertainties using a three-dimensional inverse model of the ocean circulation.

\footnotetext{
Tresently on leave at Department of Geodesy, Technical University of Delft, Delft, The Netherlands.
}

Copyright 2001 by the American Geophysical Union

Paper number $2000 . \mathrm{JC} 000556$.

0148-0227/01/2000.JC000556\$09.00
Because the model uses hydrographic data averaged over many years [Reynaud et al., 1998], the present paper is best viewed as a study of the impact of GOCE on climatological estimates of oceanic transports. It is completed by a second study (J. Schroeter et al., Impact of the Gravity Field and Steady-State Ocean Circulation Explorer (GOCE) mission on ocean circulation estimates. Volume and heat fluxes across hydrographic sections, submitted to Joumal of Geophysical. Research, 2001; hereinafter cited as J. Schroeter et al., submitted manuscript, 2001) in which the impact of GOCE is estimated using a two-dimensional inverse model constrained by model-generated synoptic hydrographic data. A third study generalizes the results found here to the global ocean through a quantitative analysis of the spatial scales that will be resolved by the mission [Le Provost and Ponchaut, 1999]. Finally, the last study explores the implications of GOCE in terms of time-dependent flows using an ocean operational forecasting system [Dombrowsky et al., 1999].

The ocean inverse modeling approach used here is described in section 2 of this paper. The main results are presented in section 3 for 14 different oceanic transects chosen to represent a wide range of oceanic processes. For each transect the impact of GOCE is examined in four layers that encompass the whole water column, the surface ocean, the upper ocean, and the deep ocean. A comparison of the impact of GOCE with the impact of the Gravity Recovery and Climate Experiment (GRACE) mission [Earth System Science Pathfinder Program, 1998; Wahr et al., 1998] is presented at 
the end of section 3. Section 4 discusses the results and concludes.

\section{Methodology}

The finite difference inverse model of the Laboratoire de Physique des Oceans (LPO) [Mercier et al., 1993; LeGrand et al., 1998] is used to evaluate the reduction of uncertainties in volume transports when uncertainties in present-clay geoid models are replaced by uncertainties expected from the GOCE mission. The approach is similar to that of LeGrand and Minster [1999], but the present study incorporates several improvements: a refined estimate of geoid height uncertainties produced during Phase $\mathrm{A}$ of the mission [European Space Agency, 1999; Space Research Organization of the Netherlands, Institute for Astronomical and Physical Geodesy, and Delft Institute for Earth-oriented Space Research (SID), 2000 ] is used; the observational constraint on dynamic topography is derived from the EGM96 [Lemoine et al., 1998] model instead of the JGM2 [Nerem ef al., 1994] one; and the resolution of the inverse model is increased from $2.5^{\circ} \times 2^{\circ}$ to $1^{\circ} \times 1^{\circ}$. This higher resolution allows a better representation of oceanic fronts and, because large uncertainty reductions are obtained in these fronts, the maximum impact estimated here is significantly larger than its counterpart found by LeGrand and Minster [1999].

The LPO finite difference inverse model has been extensively described in previous papers [Mercier et al., 1993; LeGrand et al., 1998], so only its main characteristics need to be recalled here. One important characteristic is that the model treats ocean dynamic topography as an explicit variable that can be directly constrained by observational estimates of the geoid height and of the mean sea surface height. Because dynamic topography is linked to surface velocities through the geostrophic relation, the precision of geoid height observations has a direct impact on the precision of the circulation estimated by the inverse model and thus has a direct impact on estimated transport uncertainties. To compute these uncertainties, the error spectrum of the observational constraint on dynamic topography is needed but knowledge of the actual topography is not required. The error spectrum can be derived prior to launch from the expected precision of the gravity mission and from the precision of altimetric observations, so all the information required to quantify the impact of GOCE is already available. Another characteristic of the inverse model is that it treats not only reference level velocities, but also density values as variables. Uncertainties in the vertical shear of geostrophic velocities due to uncertainties in the density field are thus taken into account and a rigorous estimate of uncertainties in transports in various layers of the ocean can be calculated.

Three calculations are discussed in the present study. The first calculation, which provides the present-day reference transport uncertainties, is constrained by an estimate of the mean dynamic topography based on the TOPEX/Poseidon (T/P) mean sea surface height and the EGM96 geoid height. This constraint is imposed within error bars consistent with the covariance matrix of the uncertainties in the EGM96 geoid height. The second calculation replaces the EGM96 geoid height uncertainties by those expected from GOCE. Because the geoid height model that GOCE will provide is not known ahead of time, the dynamic topography estimated in the reference calculation is used. This does not have a significant impact on the calculation of transport uncertainties, but it ensures the self-consistency of all the constraints of the inverse model, even when the dynamic topography constraint is imposed within the tight GOCE error bars. The third calculation is identical to the second one except that the GRACE geoid uncertainties are used instend of the GOCE ones.

For practical reasons, these three calculations have been carried out over a model domain limited to the Atlantic Ocean, including the Atlantic sector of the Circumpolar Current. Because this domain contains most of the dynamical processes present in the world ocean (deep convection, mode water formation, subpolar and subtropical gyres, and boundary currents), the conclusions reached here should remain valid over other ocean basins. This point is confirmed by a global study of the spatial scales of the ocean circulation resolved by GOCE [Le Provost and Ponchant, 1999].

The three calculations are performed using uncertainties in the mean sea surface height set to $2 \mathrm{~cm}$ to represent the precision of gridded altimetric products. This uncertainty level, which corresponds to the pointwise measurement accuracy of T/P observations, can reasonably be expected by the time GOCE is flown because improved spatial coverage and longer altimetric time series will be available then. A study of the influence of the uncertainty in altimetric gridded observations on the impact estimates is nonetheless presented in section 3.5.

The cumulative error variances corresponding to the various geoid height models used in this study are shown in Figure 1 as a function of spherical harmonic degree [Space Research Organization of the Netherlands, Institute for Astronomical and Physical Geodesy, and Delft Institute for Earth-oriented Space Research (SID), 2000]. An expansion to degree 180 is used for EGM96 and GOCE, in accordance to the resolution of the finite difference grid of the inverse model. An expansion to degree 150 is used for GRACE, higher-order expansions being unavailable when the present study was started.

Uncertainties in heat fluxes, although they would be a valuable measure of the impact of improved geoid models, are not computed here because the temperature field is not an explicit variable in the present version of the inverse model, and thus any heat flux uncertainty estimate reflects nothing more than the effect of volume flux uncertainties. A full investigation of the impact of GOCE on oceanic heat flux estimates is presented in the second paper of this series (J. Schroeter et al., submitted manuscript, 2001).

Despite the different time periods spanned by the density data (1930-1996) and the altimetric data (1993-1996), all the observational constraints implemented in the reference calculation are found to be consistent with the model dynamical constraints (essentially geostrophy and mass conservation). Because the inverse model is a steady state one, the effect of the time-variable component of the circulation appears as residuais in the dynamical constraints, and as uncertainties in the observations of the mean density field. Ideally, it would be better to model this effect, but a full-blown data assimilation approach would then be required.

The observational constraint on dynamic topography is apparently inconsistent with observed volume transports of $130 \mathrm{~Sv}$ (sverdrup, $1 \mathrm{~Sv}=10^{6} \mathrm{~m}^{3} / \mathrm{s}$ ) in the Drake Passage [Nowlin and Klinck, 1986]. In this region it seems that the 


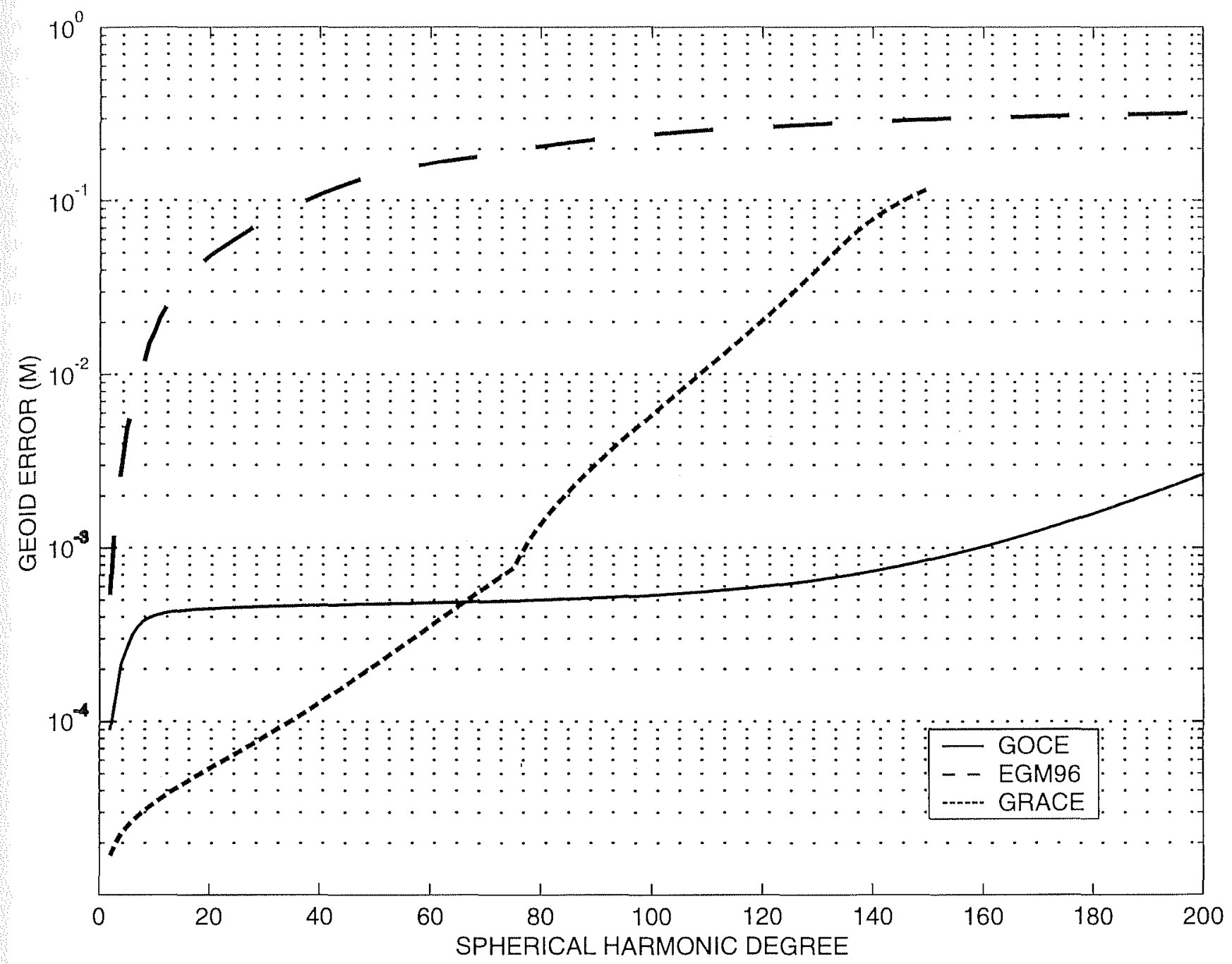

Figure 1. Cumulative geoid uncertainty as a function of the number of spherical harmonics used to construct the Gravity Field and Steady-State Ocean Circulation Explorer (GOCE) geoid model (solid line), the Gravity Recovery and Climate Experiment (GRACE) model (short-dashed line) and the EGM96 model (long-dashed line). The GOCE geoid uncertainty will be several orders of magnitude smaller than the EGM96 one at all scales and smaller than the GRACE one above spherical harmonic 60.

representation of the uncertainties in EGM96 by a simple homogeneous covariance function, which does not take into account the larger uncertainties in the Southern Ocean $(\mathrm{N}$. Pavlis, personal communication, 1999), constrains the model to reproduce too tightly the smooth dynamic topography derived from EGM96. As a consequence, surface velocities and associated volume transports across the Drake Passage are underestimated. This problem is solved by replacing, in the Southern Ocean, the T/P-EGM96 estimate of dynamic topography by an estimate derived from hydrographic data only. (For the GOCE and the GRACE calculations, the topography produced by the reference inverse calculation is used, and thus there is no consistency problem in the Drake Passage.) This approach is acceptable because it is the uncertainty in the geoid height rather than the geoid height itself that matters in the calculation of transport uncertainties, and moreover, the reference transport uncertainties are set by the hydrographic data rather than by the combination of altimetric data and geoid models [LeGrand et al., 1998].

Figure 2 shows the dynamic topography of the Atlantic estimated in the reference calculation. This map indicates the Gulf Stream gyre in the north and the Brazil Current gyre and 


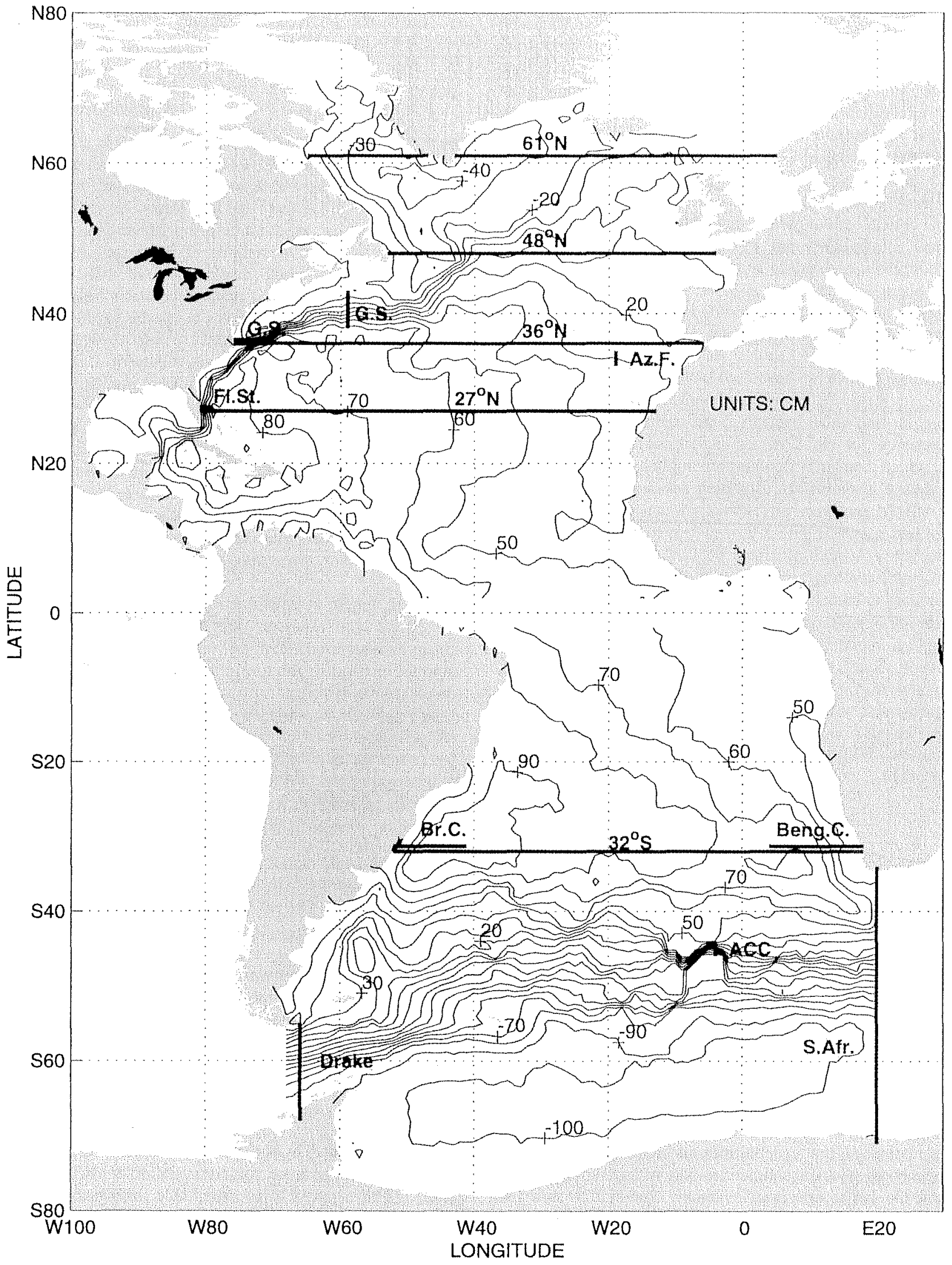

Figure 2. Mean dynamic topography estimated in the Atlantic with a $1^{\circ}$ resolution version of the Laboratoire de Physique des Oceans (LPO) inverse model based on a combination of climatological in situ data and the EGM96-TOPEX/Poseidon estimate of the mean dynamic topography. The sections across which transport uncertainty calculations are carried out are shown as thick lines. 
the fronts associated with the Antarctic Circumpolat Current (ACC) in the south. The resolution of the inverse topography estimate is more limited by the resolution of the climatology of the density field than by the resolution of the model itself. This resolution is particularly degraded in the central part of the South Allantic and in some areas of the Circumpolar Current because of the scarcity of the hydrographic database in these regions. For that reason, the pinch in the Circumpolar Current dynamic topography apparent at $5^{\circ} \mathrm{W}$ (Figure 2) is probably an artifact associated with the use of a few data points to construct the climatology of the density field in this area. No attempt was made to remove this pinch, however, because the associated currents seem to give a good indication of the intensity of currents that occur in the real ocean but tend to be underestimated in the present climatological inverse calculation.

\section{Main Results}

Figure 2 shows, superimposed on the map of dynamic topography, a number of sections through which the potential improvements in volume flux estimates have been calculated after assimilation of the crror spectrum expected from the GOCE gravity mission. Six sections have been selected in the
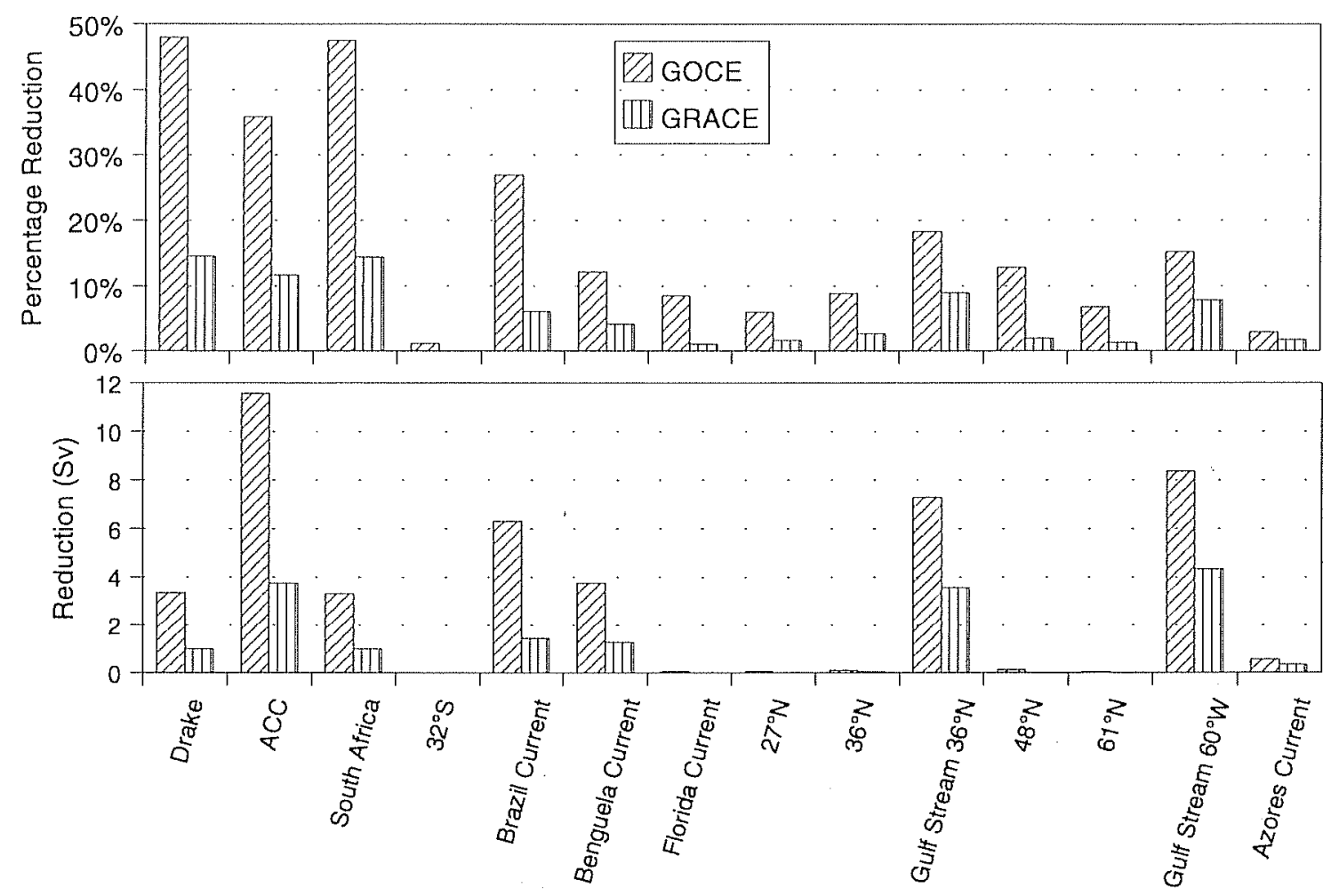

Transports estimated with EGM96

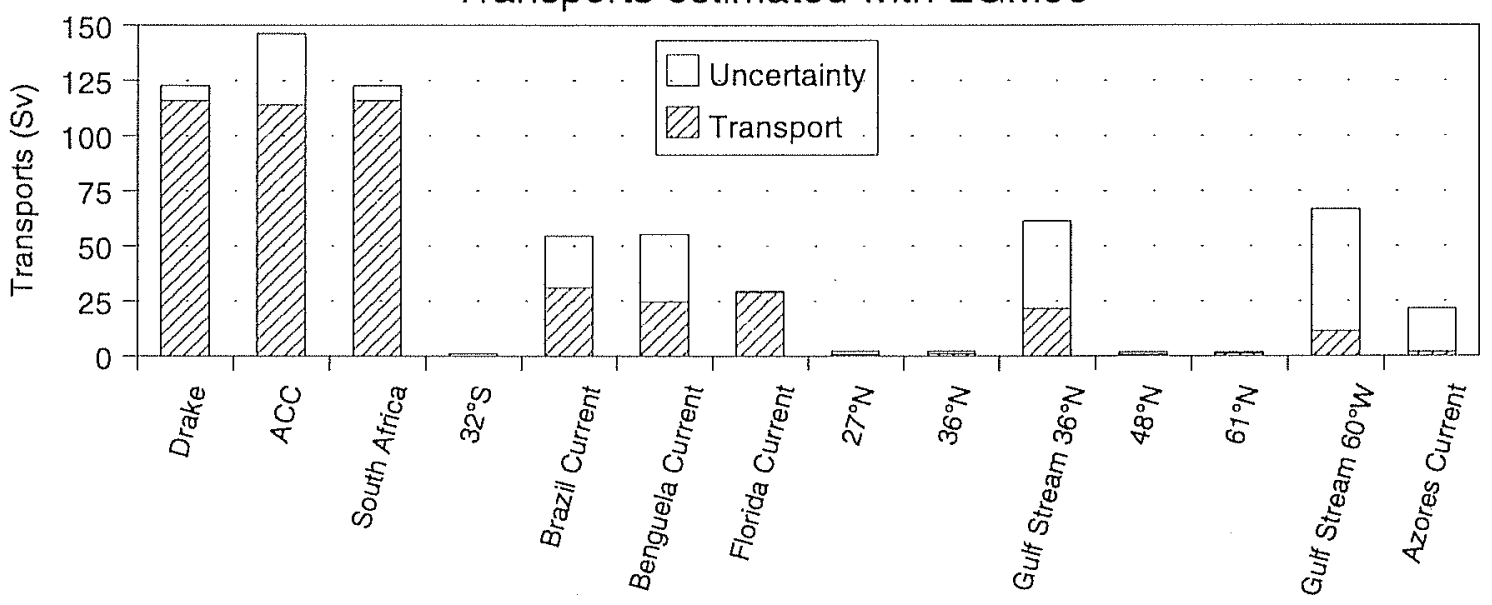

Figure 3. Impact of the GOCE and of the GRACE gravity missions on surface-to-bottom volume transports. (top) Percentage reduction of transport uncertainties relative to the EGM96 reference transport uncertainties. (middle) Corresponding absolute reduction in sverdrups. (bottom) Transports and associated uncertainties found in the reference EGM96 calculation. 
South Atlantic: the Drake Passage, a short section through the Atlantic sector of the ACC at $5^{\circ} \mathrm{W}$, the African ACC "choke point", a zonal section at $32^{\circ} \mathrm{S}$ between Africa and South America through the widest part of the subtropical gyre, and two sections at the same latitude across the Brazil Current and the Benguela Current. Eight sections have been selected in the North Atlantic: the Florida Strait, transoceanic zonal sections across $27^{\circ} \mathrm{N}, 36^{\circ} \mathrm{N}, 48^{\circ} \mathrm{N}$ and $61^{\circ} \mathrm{N}$, two sections across the Gulf Stream at $36^{\circ} \mathrm{N}$ and $60^{\circ} \mathrm{W}$, and a section across the Azores Front at $20^{\circ} \mathrm{W}$. The impact of GOCE has been quantified for four different layers: the whole water column, the upper $100 \mathrm{~m}$, the upper kilometer, and a deep layer between $3000 \mathrm{~m}$ and $4000 \mathrm{~m}$ depths.

The results of the inverse model runs are presented both as percentage reductions and absolute reductions of transport uncertainties (Figures 3 to 6 ). Percentage reductions are relative to the reference run uncertainties, indicated together with the reference transports in the bottom panels of Figures 3 to 6 . The inverse model uncertainty calculations are based on the assumptions listed in Table 1 . In the reference run, the calculated volume transport uncertainties are relatively large near the western boundary of the ocean basin and near oceanic fronts because large natural variability levels tend to increase the error bars in the climatological density field there [LeGrand et al., 1998].

\subsection{Uncertainties in Transports Integrated Over the Whole Water Column}

In the Drake Passage and in the section south of the African continent, the impact of GOCE is large (Figure 3), as expected
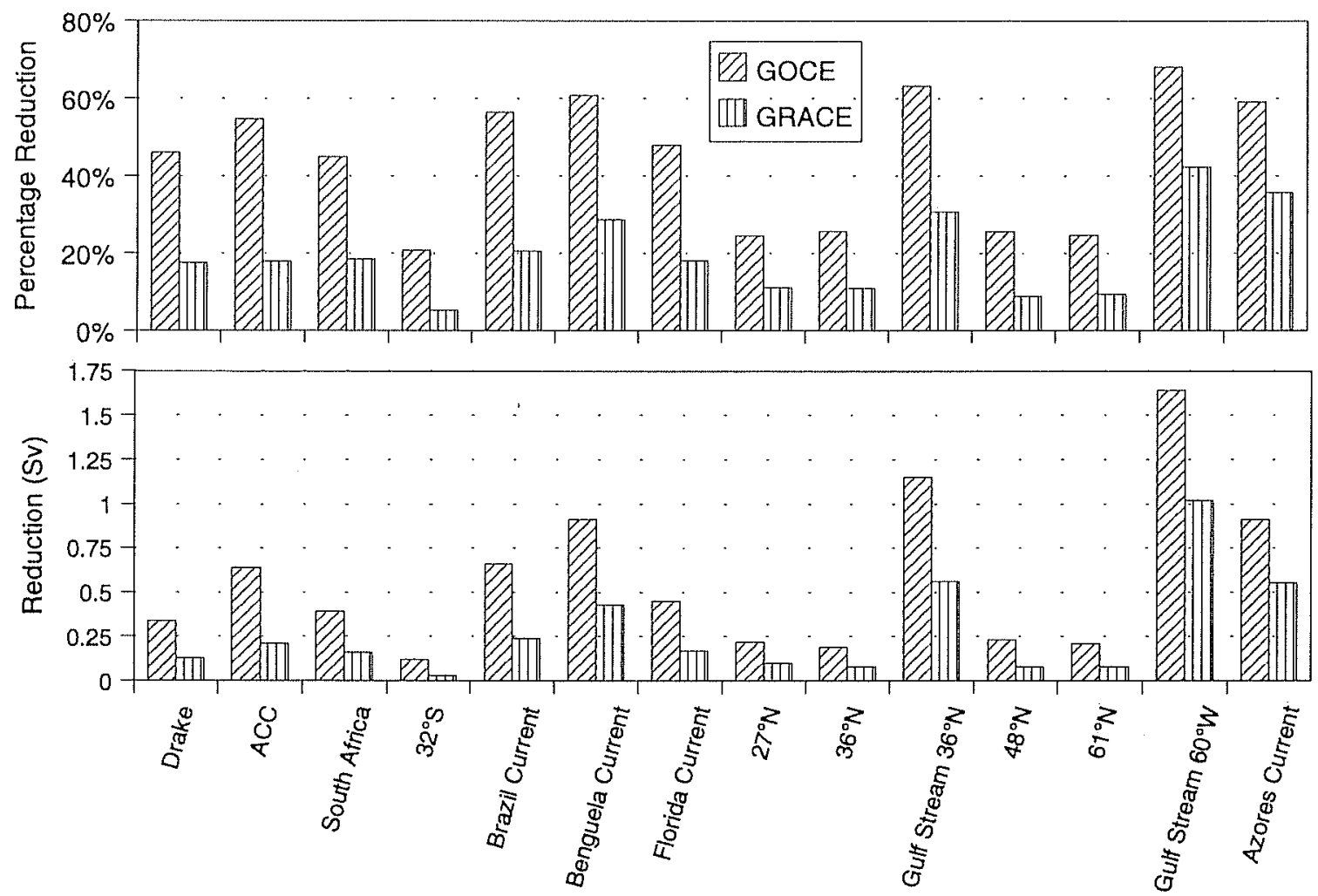

Transports Estimated with EGM96

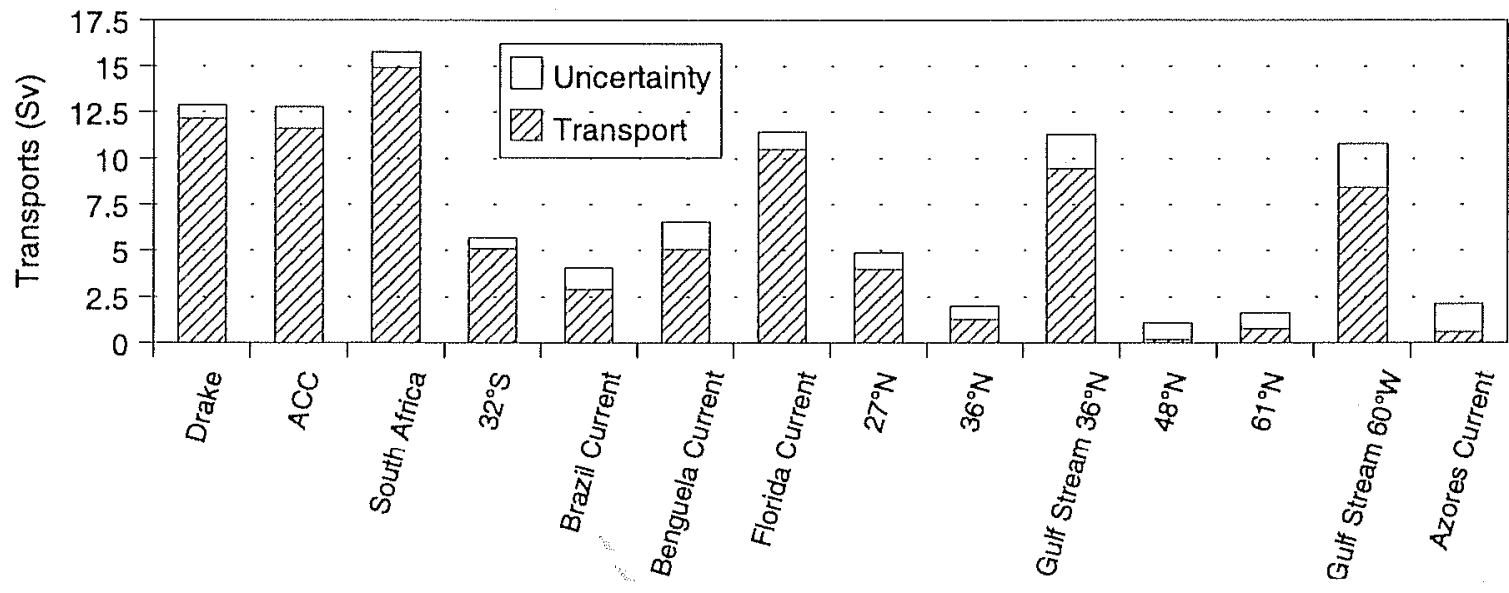

Figure 4. Same as Figure 3, but for the upper $100 \mathrm{~m}$ of the ocean. 
from the barotropic character of the Circumpolar Current. The largest absolute reduction in transport uncertainties, which is of the order of $10 \mathrm{~Sv}$, is associated with the short section across the sharp front in the $A C C$ at $5^{\circ} \mathrm{W}$. The results obtained for the ACC (Figute 3) are qualitatively consistent with the results obtained in the box inverse model study of Ganachaud et al. [1997].

The impact of GOCE on surface-to-bottom transport uncertainties is also significant in the Brazil and Benguela Currents (Figure 3). As expected, the impact of GOCE is negligible in the cross-gyre section at $32^{\circ} \mathrm{S}$ because the associated transport, which is constrained by mass conservation to be small, can only be marginally improved. Similar small impacts on transport uncertainties are found for the transoceanic sections of the North Atlantic. These results are consistent with the results obtained by LeGrand and Minster [1999] with a lower-resolution version of the LPO inverse model, although their impact estimates are even smalter because of a stricter implementation of the constraint on volume conservation across zonal sections (direct condition on volume fluxes across each zonal section instead of condition of small divergence within $1^{\circ}$ latitude bands in the present study). The smalt impact of GOCE on zonally integrated volume transports found in the present study is also consistent with the results presented in the second paper of this series (J. Schroeter et al., submitted manuscript, 2001). This later study shows that the impact of GOCE on heat transports across transoceanic sections is much larger than the
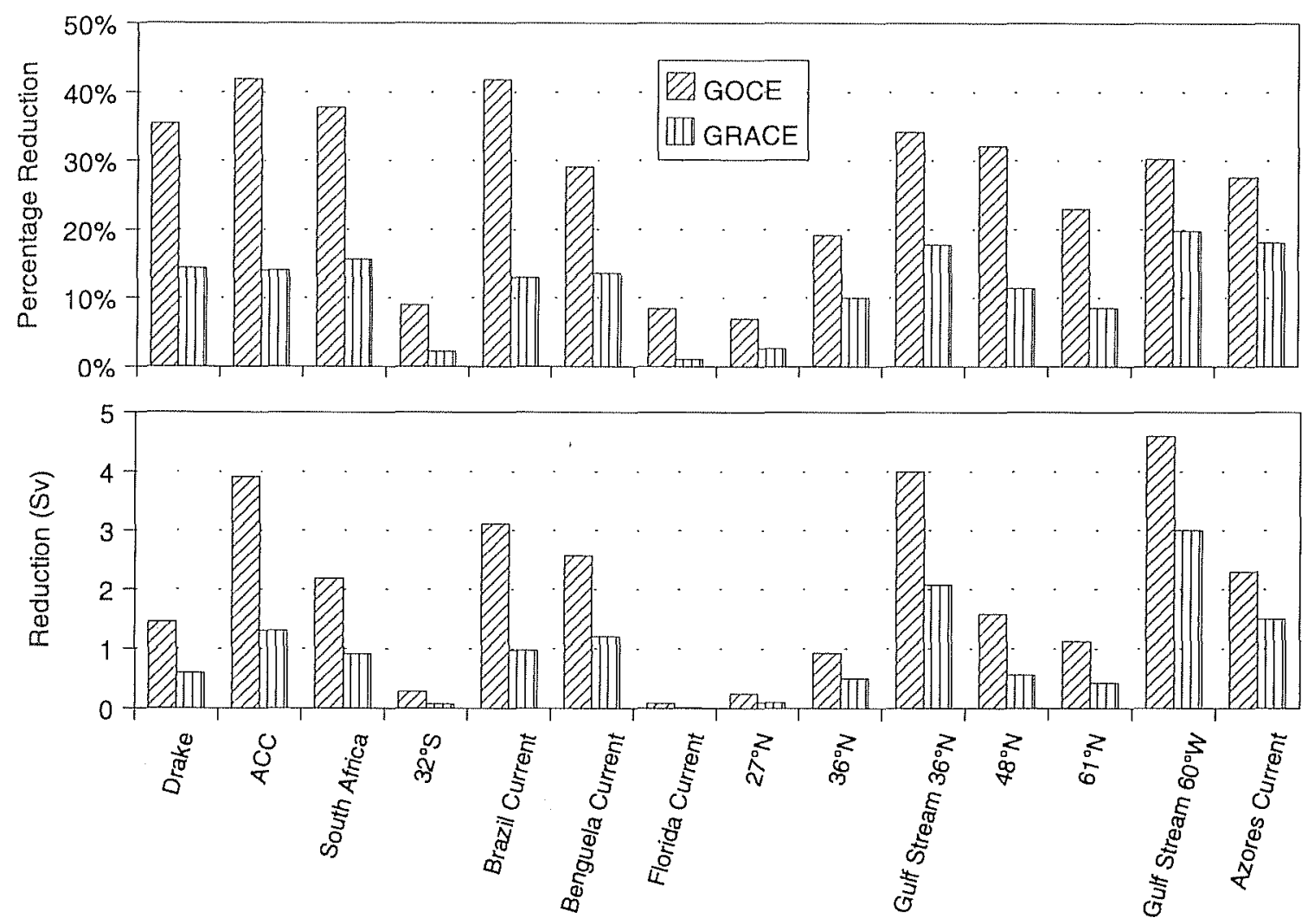

Transports Estimated with EGM96

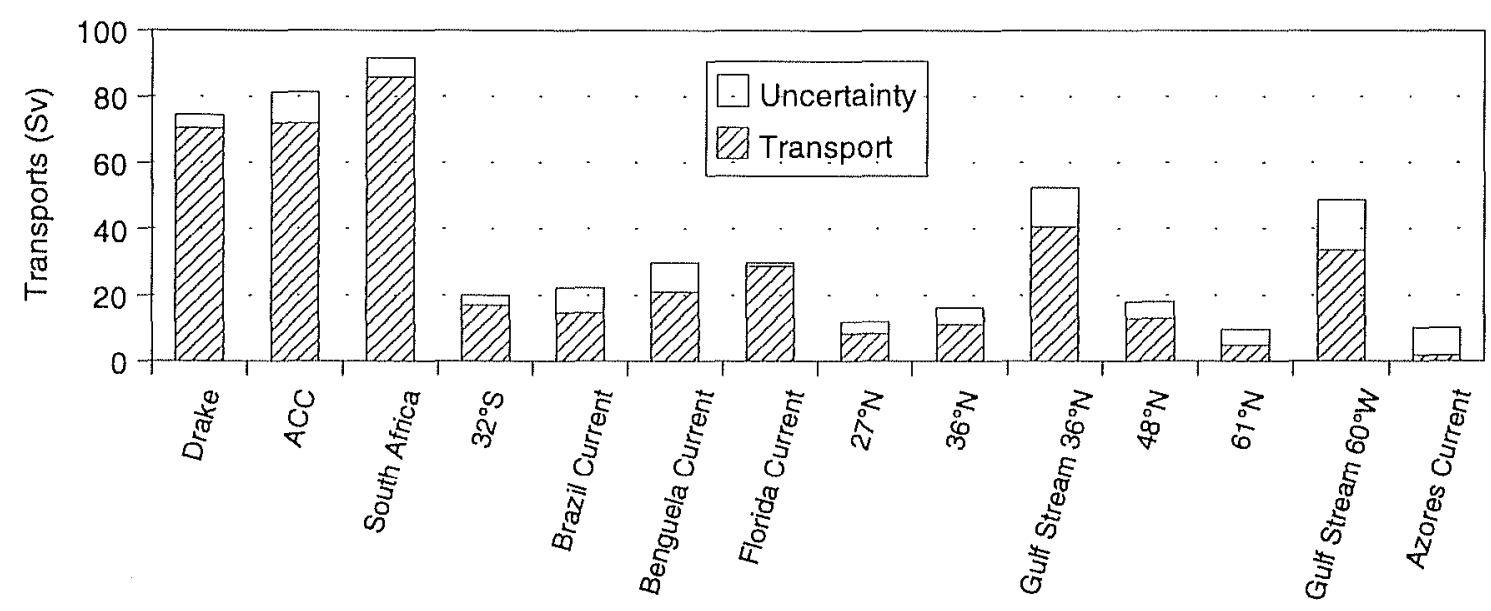

Figure 5. Same as Figure 3, but for the upper kilometer of the ocean. 
impact on volume transports. In the present study, heat fluxes are not explicitly considered, but baroclinic volume transports, which are at the origin of these heat fluxes, are investigated in the following sections.

\subsection{Uncertainties in Transports in the Upper Layers of the Ocean}

Improvements in geostrophic volume transports provided by GOCE in the upper $100 \mathrm{~m}$ of the water column are shown in Figure 4. Ekman transports, which cannot be determined by altimetric observations alone because they have no direct signature on sea surface topography, are added to the geostrophic transports in the upper layer of the model $(30 \mathrm{~m}$ deep). The uncertainties in these transports translate into uncertainties in the volume conservation constraints (Table 1).
The divergence of $1 \mathrm{~Sv}$ tolerated a priori within a $1^{\circ}$ latitude band is as large as the order of magnitude of the zonally integrated geostrophic transports in the upper $100 \mathrm{~m}$ of the water column (Figure 4). Uncertainties in Ekman transport estimates may thus limit improvements of total transport estimates in the ipper ocean. One may, however, expect that Ekman transports will become better known as the coverage of scatterometer observations improves. In the opposite case, highly precise geostrophic transport estimates will still be useful because they will provide constraint on Ekman fluxes through mass conservation.

A large reduction of the uncertainties in geostrophic transports is found in the upper $100 \mathrm{~m}$ of the ocean (Figure 4). The impact of GOCE reaches about $60 \%$ in the Benguela Current, which exhibits the largest relative uncertainty
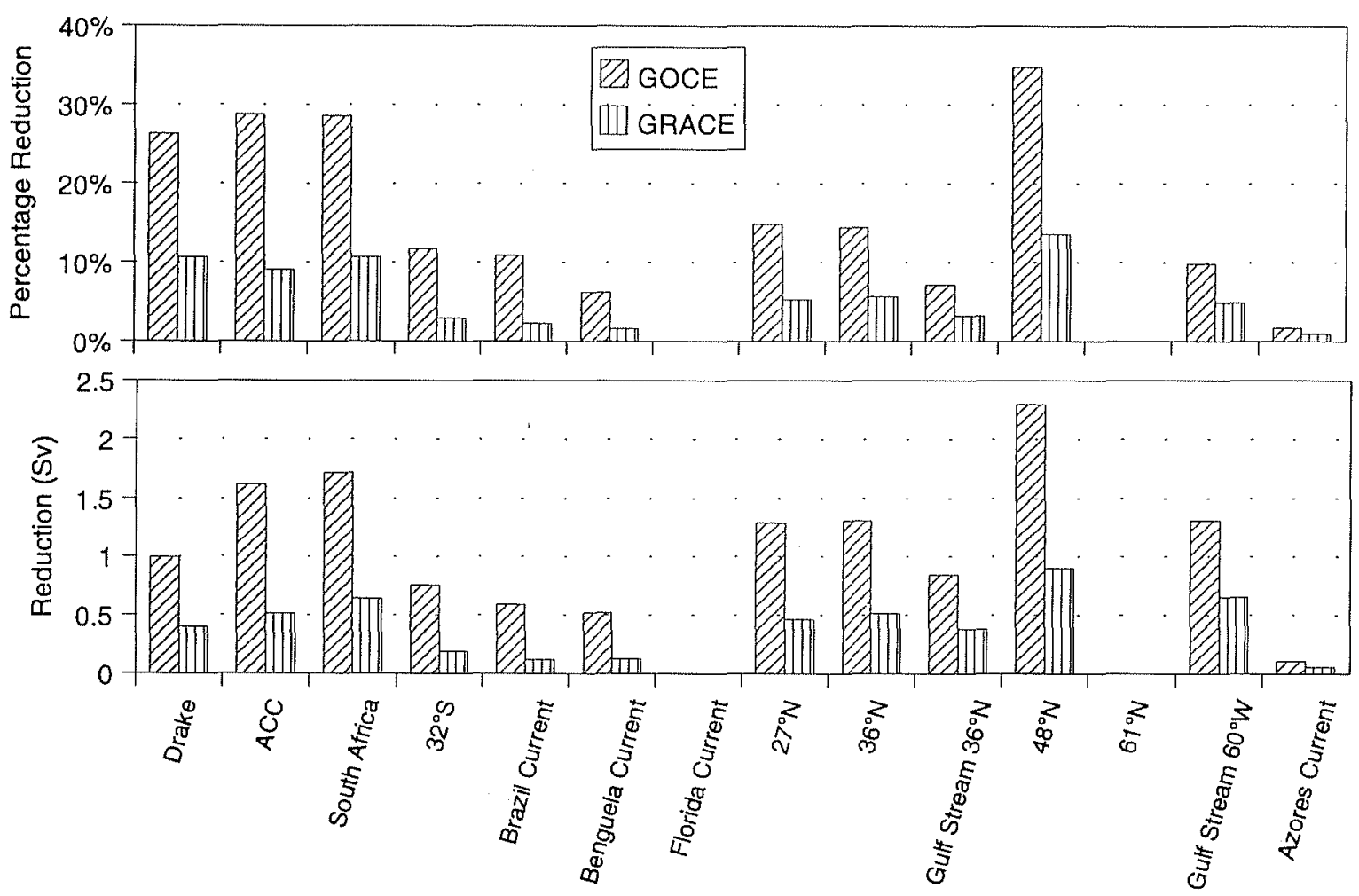

Transports Estimated with EGM96

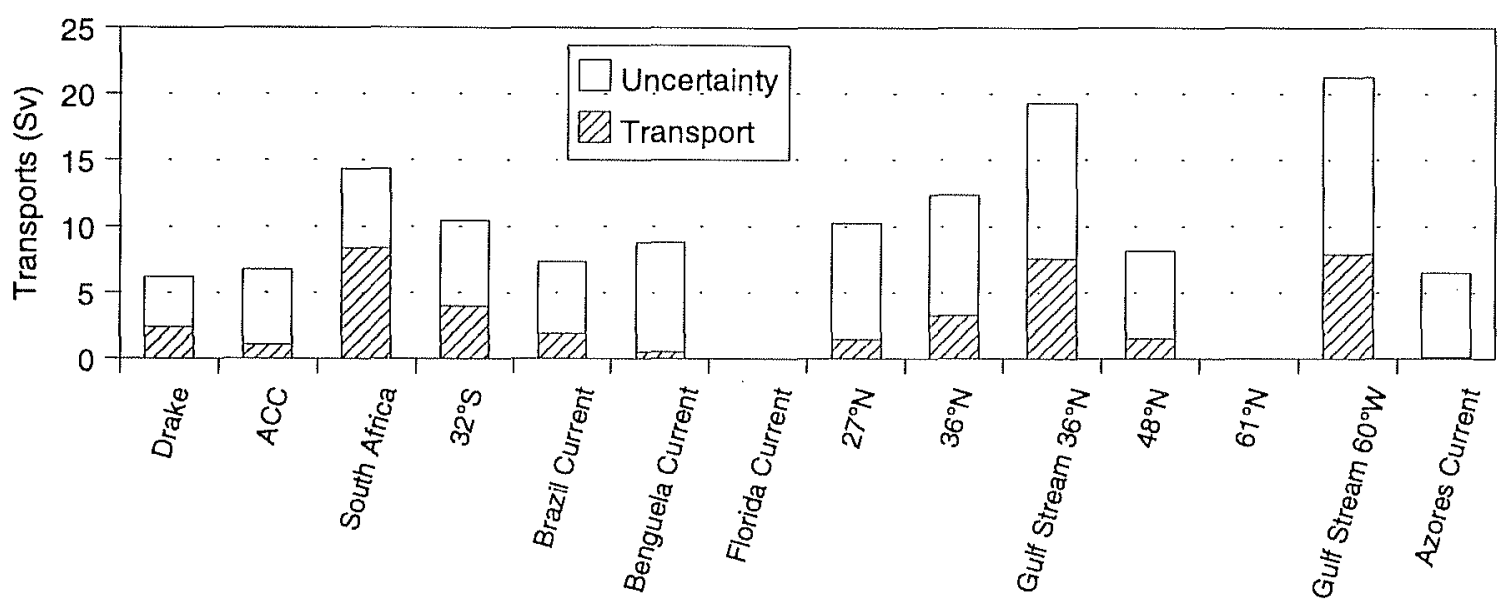

Figure 6. Same as Figure 3, but for the layer between depths of $3000 \mathrm{~m}$ and $4000 \mathrm{~m}$. 
Table 1. Assumptions Made in the Reference Inverse Calculation.

\begin{tabular}{|c|c|}
\hline Parameters & Assumptions \\
\hline Reference level velocities & $\begin{array}{l}\text { Standard deviations of } 3 \mathrm{~cm} / \mathrm{s} \text { in the interior, and } 20 \mathrm{~cm} / \mathrm{s} \text { near the western boundary (values } \\
\text { selected by trial and error). No correlation of uncertainties. Reference level is at } 1500 \mathrm{~m} \text { depth in } \\
\text { the Atlantic and } 4000 \mathrm{~m} \text { depth in the Antarctic Circumpolar Current. }\end{array}$ \\
\hline Density field & $\begin{array}{l}\text { For each grid point, standard deviations of density field calculated using hydrographic data } \\
\text { available within a radius of influence [Reynaud et al., 1998]. An empirical orthogonal function } \\
\text { (EOF) decomposition of these standard deviations is then carried out. A projection of the density } \\
\text { field and associated uncertainties onto the resulting EOF modes yiclds EOF coefficients and } \\
\text { associated uncertainties that are then fed to the inverse model. Vertical correlations of } \\
\text { uncertainties implicitly contained in EOF decomposition. No horizontal correlation of } \\
\text { uncertainties. }\end{array}$ \\
\hline Dynamic topography & $\begin{array}{l}\text { Uncertainties determined by covariance function of uncertainties in EGM96 geoid model (Figure 1). } \\
\text { Standard deviations of } 2 \mathrm{~cm} \text { are added to the diagonal of the resulting uncertainty covariance } \\
\text { matrix in order to simulate the noise in altimetric estimates of sea surface height at the time of } \\
\text { GOCE. }\end{array}$ \\
\hline Local volume conservation & $\begin{array}{l}\text { Error bars in Ekman velocities of the order of } 1 \mathrm{~cm} / \mathrm{s} \text {, which translates into uncertainties in volume } \\
\text { conservation constraints of } 3 \times 10^{4} \mathrm{~m}^{3} / \mathrm{s} \text { (conservation within } 1^{\circ} \times 1^{\circ} \text { boxes, from the surface to the } \\
\text { bottom of the ocean). These uncertainties are low in order to simulate the high accuracy of Ekman } \\
\text { velocity estimates that could be achieved at the time of GOCE. }\end{array}$ \\
\hline Large-scale volume transports & $\begin{array}{l}\text { Nondivergence of volume fluxes in } 1^{\circ} \text { latitude bands imposed within an error bar of } 1 \mathrm{~Sv} \text { (1 Sv is } \\
\text { the order of magnitude of the standard deviation of the annual mean of zonally integrated Ekman } \\
\text { transports cited by Trenberth et al. [1989]). Transports across the Drake Passage and south of the } \\
\text { Cape of Good Hope are set to } 130 \mathrm{~Sv} \text { with a } 20 \text { Sv error bar. }\end{array}$ \\
\hline
\end{tabular}

reduction among all the sections considered in the South Atlantic. This result is consistent with the idea that the impact will be larger for transports in narrow and intense currents because of the high resolution of the GOCE mission.

The impact on transport uncertainties in the upper $100 \mathrm{~m}$ is also large in the North Atlantic, with the largest relative impact reaching almost $70 \%$ in the Gulf Stream at $60^{\circ} \mathrm{W}$. This result indicates that GOCE will provide precise constraints on the dynamics of this region of intense air-sea interactions. The impact is limited in absolute terms because geostrophic transports in the upper $100 \mathrm{~m}$ of the water column are small. It is, however, a good indicator of the impact on larger transports that occur between the surface of the ocean and depths of several hundred meters (not shown here).

The impact found for the transoceanic sections is generally consistent with the results of LeGrand and Minster [1999]. One exception occurs at $36^{\circ} \mathrm{N}$, where the uncertainty reduction they found is less than $5 \%$ whereas the reduction found here is larger than $20 \%$. This discrepancy is likely due to the low resolution of their model, which does not properly resolve the Gulf Stream at this latitude. Their transport uncertainty is thus underestimated in the reference run because of the omission of the uncertainties associated with the fine-scale transports near the western boundary. As a consequence, there is less room for improvement by a gravity mission and the impact of GOCE is underestimated.

\subsection{Uncertainties in Transports in the Upper Kilometer of the Ocean}

Transports in the upper kilometer of the Atlantic can be interpreted as representing the upper branch of the overturning cell. The uncertainties in these transports (Figure 5) are only a small fraction of the overturning rate, which indicates that this rate is already fairly well known. These uncertainties are nonetheless large in terms of our knowledge of the climate system, and, maybe more importantly, in the context of the detection of potential climate changes. Indeed, a climate change of the order of the present-day uncertainties would have a large effect on the environment because the transport of heat associated with the overturning circulation is huge.

The impact of GOCE on volume transport uncertainties in the upper kilometer of the ACC is significant, with a reduction of the order of $40 \%$ in relative terms and of the order of $1 \mathrm{~Sv}$ to $4 \mathrm{~Sv}$ in absolute terms (Figure 5). An equally large impact is found in narrow currents of the Atlantic: several sverdrups in absolute terms in the Brazil and Benguela Currents; almost a factor of 2 in relative terms in the Brazil Current (Figure 5); and about $35 \%$ in relative terms and about $4 \mathrm{~Sv}$ in absolute terms in the Gulf Stream at $36^{\circ} \mathrm{N}$. The largest absolute impact, which occurs in the Gulf Stream at $60^{\circ} \mathrm{W}$, is close to $5 \mathrm{~Sv}$. The impact on fluxes across transoceanic sections is smaller than the impact across narrow currents, but it is still significant. At $48^{\circ} \mathrm{N}$, for instance, it is of the order of $2 \mathrm{~Sv}$. Assuming that the northward transport of relatively warm water in the Gulf Stream is compensated by a return flow of deep water $12^{\circ} \mathrm{C}$ colder, this $2 \mathrm{~Sv}$ uncertainty reduction translates into a reduction in heat flux uncertainties of about $10^{14} \mathrm{~W}$, which is significant at this latitude.

The impact of GOCE is smaller at $27^{\circ} \mathrm{N}$ than at the other North Atlantic transoceanic sections. This result is probably due to a local underestimation of the rate of overturning by the inverse model, this rate being less than $10 \mathrm{~Sv}$ at $27^{\circ} \mathrm{N}$ but between $15 \mathrm{~Sv}$ and $20 \mathrm{~Sv}$ further north and further south. This underestimation is caused by the absence of a significant Deep Western Boundary Current atround $27^{\circ} \mathrm{N}$, which is itself caused by a poor representation of the horizontal density gradients in the Reyncul et al. [1996] climatology in this region. The underestimated overturning at $27^{\circ} \mathrm{N}$ translates into small local uncertainties in reference volume transports $(3.4$ Sv at $27^{\circ} \mathrm{N}$ instead of $4.9 \mathrm{~Sv}$ both at $36^{\circ} \mathrm{N}$ and at $48^{\circ} \mathrm{N}$; Figure 

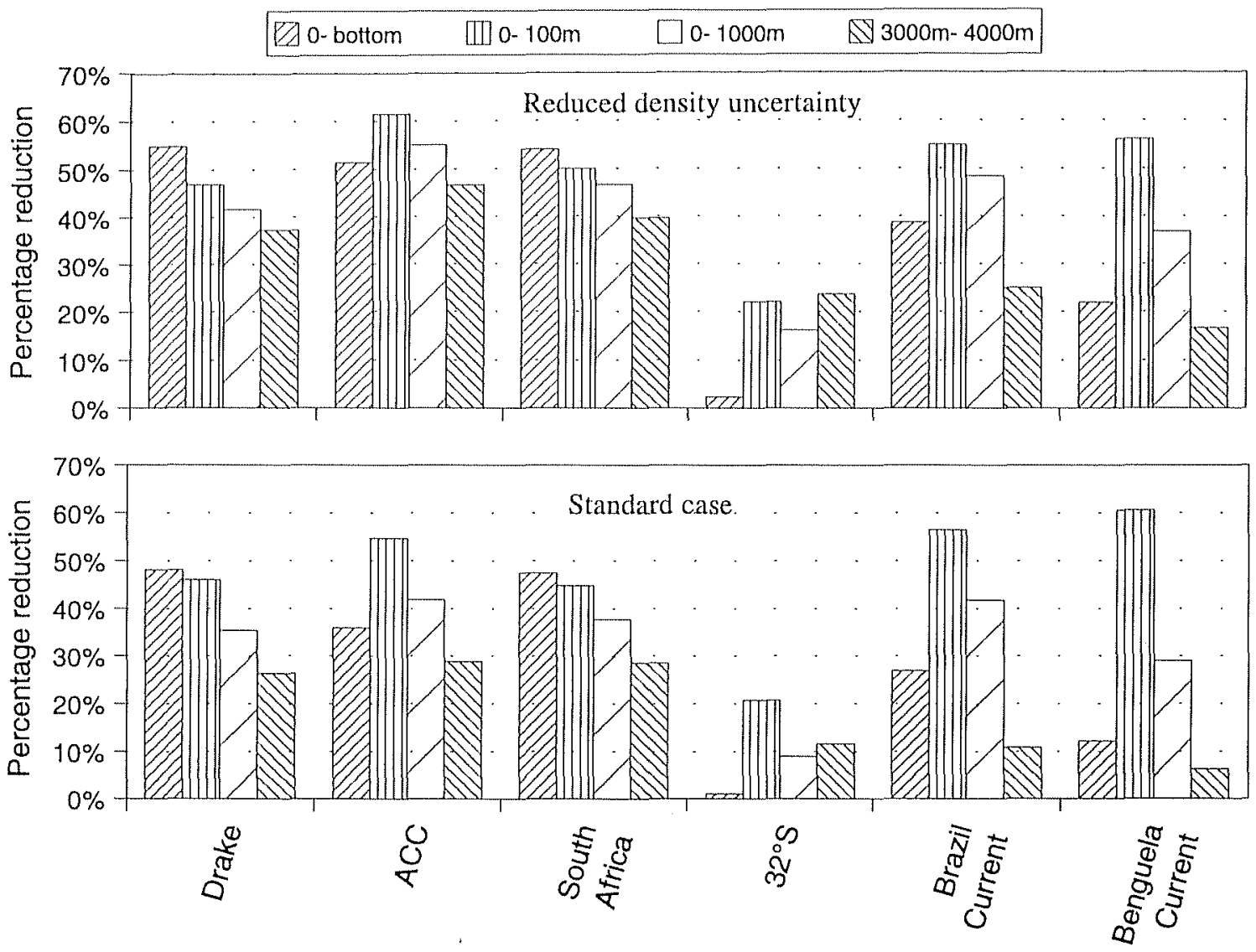

Figure 7. Impact of GOCE estimated by the inverse model in the South Atlantic when the uncertainty in the density field is reduced by a factor of 2 . The bar plots show relative uncertainty reductions for the different layers indicated in the legend. (top) Reduced density uncertainty case. (bottom) Standard case for comparison. The standard case relative uncertainty reductions are identical to those presented in a different order in the top panels of Figures 3 to 6.

5). The estimate of the impact of GOCE on transports across $27^{\circ} \mathrm{N}$ should therefore be interpreted with some caution.

The impact found at $36^{\circ} \mathrm{N}$ and at $48^{\circ} \mathrm{N}$ in the present estimate is larger than the impact found by LeGrand and Minster [1999]. As in the upper $100 \mathrm{~m}$ layer, these differences are explained by the higher resolution of the present model, which properly resolves the dynamics of the western boundary region. These differences are also explained by larger uncertainties in the density field, the $1^{\circ} \times 1^{\circ}$ climatology used here accounting for some natural variability at relatively small spatial scales that was not present in the $2.5^{\circ} \times 2^{\circ}$ climatology used by LeGrand and Minster [1999].

The impact on transport uncertainties in the layer below 1 $\mathrm{km}$ depth (not shown here) is very similar to the impact in the upper kilometer for all the Atlantic transoceanic sections. This similarity arises because transports in the upper ocean and transports in the deep ocean must balance each other in order to conserve mass, the northem side of the basin being almost closed.

\subsection{Uncertainties in Transports in the Layer Between $3000 \mathrm{~m}$ and $4000 \mathrm{~m}$ Depths}

The impact of GOCE on transport uncertainties is significantly smaller in the $3000 \mathrm{~m}$ to $4000 \mathrm{~m}$ layer (Figure 6) than in other layers, both in barotropic regions like the ACC and in baroclinic regions like the Atlantic. This result, which indicates that the impact of a precise dynamic topography estimate decreases with depth, is explained by the dilution of information occurring during the integration of the thermal wind balance [LeGrand and Minster, 1999]. Indeed, because the noise in the mean density field is associated with variability which is often caused by vertically coherent structures like baroclinic waves, it tends to be vertically correlated and its effect accumulates as the depth range over which the thermal wind balance is integrated increases.

One exception occurs at $48^{\circ} \mathrm{N}$, where the impact found is of the same order of magnitude in the $3000 \mathrm{~m}$ depth to $4000 \mathrm{~m}$ depth layer and in the upper ocean. This result suggests that the transport in the $3000 \mathrm{~m}$ and $4000 \mathrm{~m}$ layer, which is practically the bottom layer at this latitude, is closely linked to the transport in the upper layers of the ocean. One explanation may be that the northward flux of water in the upper ocean across $48^{\circ} \mathrm{N}$ is matched by the amount of deepwater production to the north, and thus matched by the net amount of water that is exported southward in the bottom layer. A more detailed budget of volume fluxes in the northern part of the North Atlantic would be necessary before drawing definite conclusions, but proceeding to this level of detail is beyond the scope of the present study. 
The volume transport uncertainties in the reference calculation are 3 to 4 times larger here than in the work by LeGrand and Minster [1999]. As in the upper layers of the ocean, these larger reference transport uncertainties result from a better representation of the western intensification of the circulation and larger and more realistic density uncertainties. An additional factor more specific to the deep ocean is that larger uncertainties in reference level velocities can be tolerated in the present higher-resolution model without necessarily causing unrealistically large barotropic transports because the section area seen by velocity vector at each grid point is smaller than in the low resolution model. As a result, the impact of GOCE found here for the $3000 \mathrm{~m}$ to $4000 \mathrm{~m}$ layer is generally larger than its counterpart found by LeGrand and Minster [1999].

\subsection{Sensitivity Tests}

A sensitivity test has been carried out to determine the influence of the uncertainties in the density field on the calculation of the impact of GOCE. Figure 7 shows that in the South Atlantic the impact of GOCE when the uncertainties in the density field ate reduced by a factor of 2 does not differ much from the standard estimate in the upper layers but it does decrease less rapidly at depth. This result shows the better propagation of the information on surface velocities toward the deep layers of the ocean when uncertainties in the velocity shear associated with uncertainties in the density field are reduced.
Another sensitivity test has been carried out to determine the influence of the uncertainty in the altimetric estimate of sea surface height. Figure 8 shows the impact of GOCE in the South Atlantic when the uncertainty in sea surface height is assumed to be determined by the level of natural variability calculated using the first 4 years of $\mathrm{T} / \mathrm{P}$ data (Figure 9) instead of the $2 \mathrm{~cm}$ level used in the standard calculations. This level of natural variability, which mostly reflects seasonal variability, can be thought of as an upper bound on the actual uncertainty in mean sea surface height (the uncertainty in the mean tends to decrease as altimetric time series span more and more seasons). The impact of GOCE on transport uncertainties presented in the upper panel of Figure 8 is generally smaller by a factor of 2 than the standard impact presented in the lower panel. The uncertainty in altimetric estimates of mean sea surface height, although it is presently small compared to the uncertainty in geoid height models, may thus become a limiting factor when precise gravity field estimates become available.

\subsection{Estimate of the Impact of GRACE}

Figures 3 to 6 also show an estimate of the impact of GRACE for the 14 sections considered in this study. This impact is calculated with a geoid error spectrum corresponding to a cutoff at degree 150 rather than a cutoff at degree 180 . Omission errors between degree 150 and degree 180 are thus neglected, and the impact of GRACE is presumably overestimated.
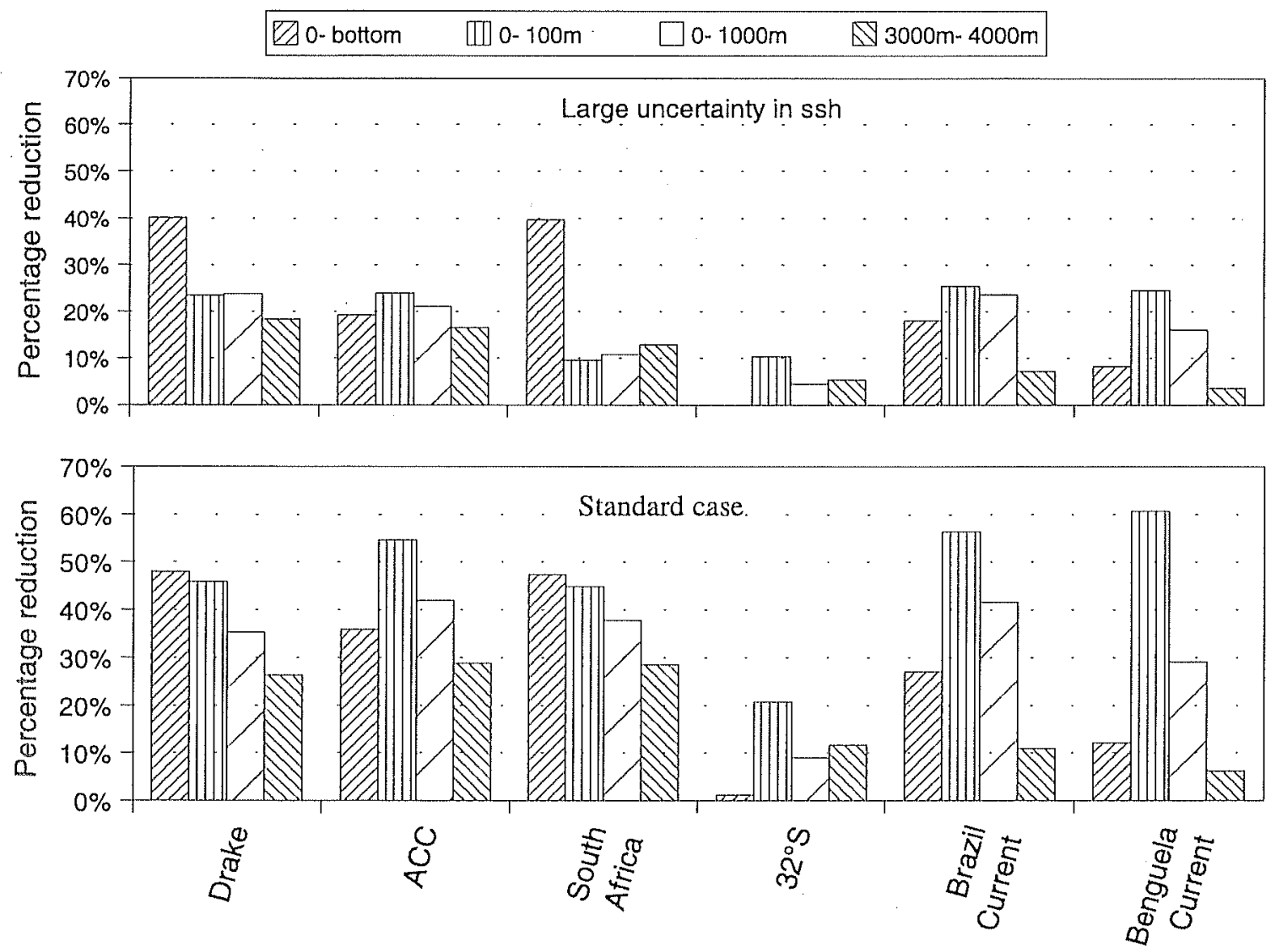

Figure 8. Impact of GOCE estimated by the inverse model in the South Atlantic when the assumption of a uniform uncertainty in sea surface height (ssh) of $2 \mathrm{~cm}$ is replaced by an uncertainty estimate corresponding to the levels of natural variability in TOPEX/Poseidon ssh observations. Presentation of the results as in Figure 7. 


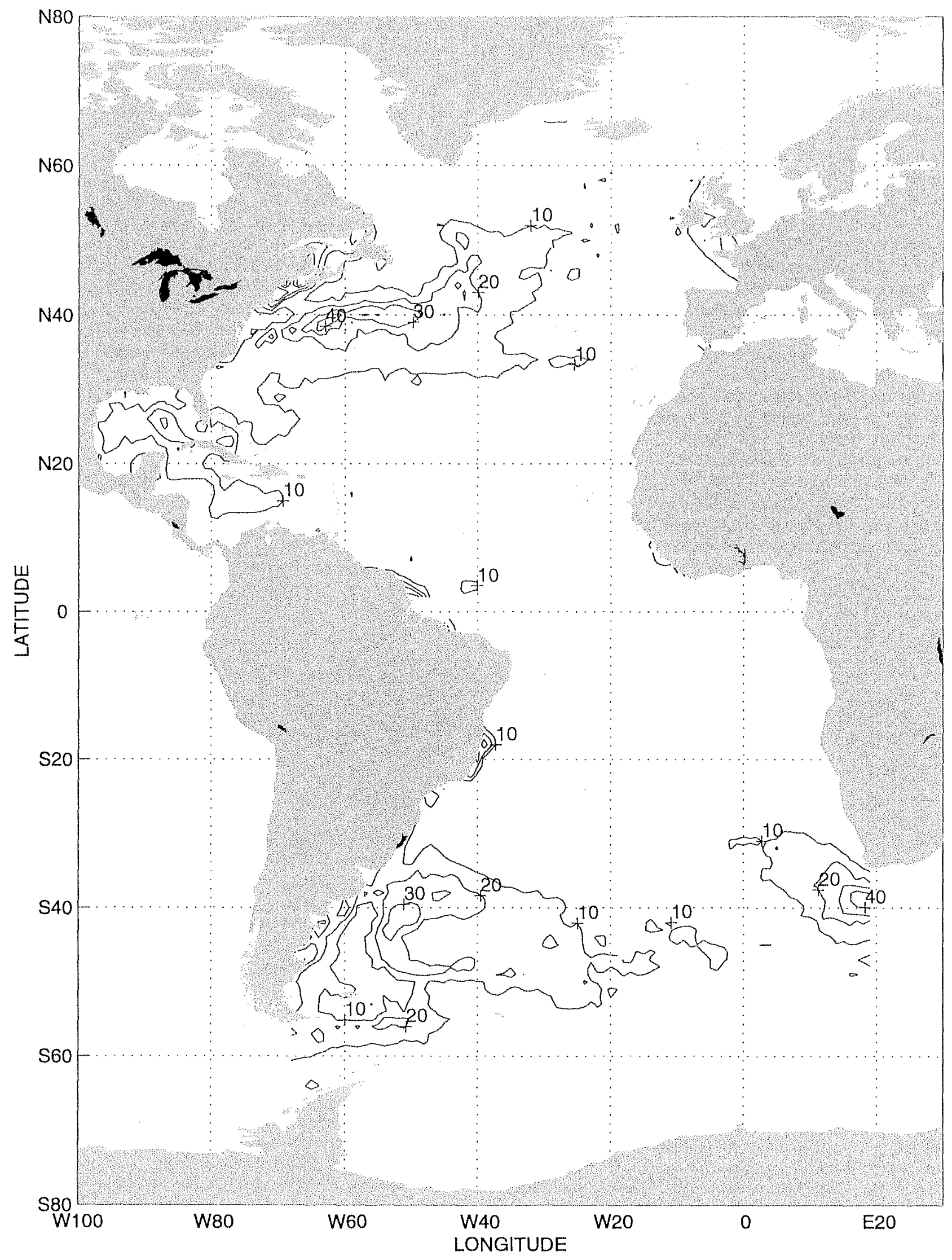

Figure 9. Standard deviation of the T/P altimetric estimate of sea surface height averaged over $1^{\circ} \times 1^{\circ}$ boxes. These deviations, which are due to the natural variability of the ocean, are larger near sharp frontal zones like the Gulf Stream, the Brazil Current - Falkland Current region, and the Agulhas Current. 
Even with the degree 150 to degree 180 omission errors being neglected, the impact of GRACE is less than hall that of GOCE. This result is due to the larger uncertainties expected for GRACE at small spatial scales (Figure 1). Except for their difference in magnitude, the impacts of GRACE and GOCE are qualitatively similar, the smallest impacts being usually associated with deep ocean transports and the largest impacts being associated with upper ocean transports. This similarity is not surprising since the vertical structure of the currents, which is determined by the horizontal gradients of density and the model conservation equations, is similar in the two calculations. Unlike what is found for GOCE, however, the impact of GRACE on relative transport uncertainties in the upper layers of the ACC is no larger in the short section at $5^{\circ} \mathrm{W}$ than in the longer sections of the Drake Passage and the South African ACC choke point. This result may be a consequence of the lower resolution of GRACE, which limits its impact on small spatial scales. It is not confirmed, however, by the section across the Azores Front in the upper ocean for which the impact of GRACE is more than $50 \%$ of the impact of GOCE.

\section{Conclusion}

The impact of GOCE on volume transport uncertainties will be significant in the Atlantic, and in the ACC, especially in the upper layers of the ocean, where it will reach over $50 \%$ in some regions. In absolute terms, the impact will reach several sverdrups in the upper kilometer of the ocean. Regions' where the impact of GOCE will be largest correspond to intense and narrow oceanic currents, as expected from the high resolution of the mission. Transport estimates across transoceanic sections will also be improved because the uncertainties in these transports are often dominated by uncertainties in narrow western boundary currents. The impact of GOCE on volume transport uncertainties will be roughly twice the impact of GRACE, and probably more if a geoid height uncertainty corresponding to an expansion up to spherical harmonic degree 180 were used for GRACE instead of an expansion up to degree 150 . This result is not surprising since the main goal of GRACE is not to improve climatological estimates of the circulation but rather to observe temporal variations of the large-scale ocean circulation. A thorough comparison of the spatial scales resolved by GOCE and by GRACE [Le Provost and Ponchaut, 1999] further elaborates on this point and generalizes the conclusions presented here to the global ocean.

The only volume transport uncertainties that will not be much reduced by GOCE in the Atlantic are uncertainties in transports across transoceanic zonal sections integrated from the surface to the bottom of the ocean. Indeed, these uncertainties are small prior to the implementation of any constraint on dynamic topography because of the condition of small net flux of mass across the northem boundary of the Atlantic. This point explains the small impact found by Ganachatud et al. [1997] (in their section 6, fourth paragraph) in terms of zonally-integrated mass transports, although the impact found in their study is slightly larger because they make the assumption that error bars in the density field are very small in order to explore the best possible outcome of future gravity missions.

The impact of GOCE on heat fluxes is not explicitly investigated in the present study because of the limitations of the inverse model. However, unlike some more conventional models, the present model allows a proper estimation of baroclinic transport uncertainties. The impact of GOCE on the transports of volume by the upper branch of the meridional overturning cell has thus been estimated. It is consistent with the reduction in heat flux uncertainties found by Ganachaud et al. [1997] and by J. Scliroeter et al. (submitted manuscript, 2001). The present results suggest that the improvements in heat flux estimates previously found are linked to improvements in estimates of the meridiona! overturning.

An illustration of how GOCE will improve our knowledge of the climate system is obtained by looking at the exchange of water masses between the Circumpolar Current and the South Atlantic. In this region, the several sverdrups of transport uncertainty reduction predicted for the Circumpolar, the Brazil, and the Benguela Currents, although they ate small compared to the absolute transports, are comparable in magnitude with the $10 \mathrm{~S} v$ of water exchanged between the Southern Ocean and the Atlantic Ocean [Saunders and King, 1995]. GOCE will thus improve estimates of the northward flux of upper waters entering the Atlantic Ocean and better constrain the two contradictory schemes that have been proposed for the origin of these waters: the warm water path [Gordon, 1986; Speich et al., 2001] which argues that these waters originate from the Indian Ocean and enter the Atlantic through the Agulhas Current, and the cold water path [Rintoul, 1991; Speich et al., 2001] which argues that they originate from the South Pacific and enter the Atlantic through the Drake Passage. One outcome of the GOCE mission may thus be a definite answer to the question of which path is dominant.

Despite very positive conclusions on the impact of gravity missions, this study points to the need for in situ observations to complement altimetry/gravity observations of the circulation at the surface of the ocean. Indeed, the sensitivity test carried out in section 3.5 shows that a precise estimate of the density field allows a better propagation of the information on surface velocities to the deep layers of the ocean. Such a precise estimate can be provided by synoptic observations of the instantaneous density field which unlike climatological observations, are not subject to the uncertainty caused by the natural variability. The deployment of the Argo [Argo Science Team, 1998] network of profiling floats, which should be well under way by the time GOCE is flown, will therefore be complementary with the observations of dynamic topography provided by the Jason altimeter and the GOCE gradiometer.

Acknowledgments. This work was supported by a grant of the European Space Agency (ESTEC contract 13175/98/NL/GD). The inverse calculations were carried out on the J90 Cray of the CNES center (French Center for Space Studies) and on the C90 of the IDRIS center (French Institute for Scientific Computing). J. Toumadre provided the estimate of sea surface height variability shown in Figure 9. I am grateful to the members of the GOCE Mission Advisory Group for their encouragement throughout this work, and to A. Ganachaud and an anonymous reviewer who helped me to improve a preliminary version of this paper.

\section{References:}

ARGO Science Team, On the design and implementation of Argo: An initial plan for a global array of profiling floats, Int. CLIVAR Proj. 
Off. Rep. 21, GODAE Rep. 5, 32 pp., GODAE Int. Proj. Off., Melbourne, Vict., Australia, 1998.

Dombrowsky, E., S. Giraud, and G. Dibarboure, Impact of the GOCE mission for ocean circulation study, final report, ESTEC contract 13175/98/NL/GD, Eur. Space Res. And Technol. Cent., Noordwijk, Netherlands, 1999

Earth System Science Pathfinder Program GRACE, Gravity Recovery and Climate Experiment: Science and mission requirements document, revision A, Rep. IPLD-15928, NASA, Washington D.C., 1998

European Space Agency, The four candidate Earth Explorer Core Missions - Gravity field and steady-state Ocean Circulation Explorer, Eur. Space Agency Spec. Publ., ESA SP - 1233, 217 pp., 1999.

Ganachaud, A., C. Wunsch, M.-C. Kim, and B. Tapley, Combination of TOPEX/Poseidon data with a hydrographic inversion for determination of the oceanic general circulation and its relation to geoid accuracy, Geophys. J. Int., 128, 708-722, 1997

Gordon, A.L., Interocean exchange of thermocline water, J. Geophys. Res., 91, 5037-5046, 1986.

LeGrand, P., and J.-F. Minster, Impact of the GOCE gravity mission on ocean circulation estimates, Geophys. Res. Lett., 26, 1881 1884,1999

LeGrand, P., H. Mercier, and T. Reynaud, Combining T/P altimetric data with hydrographic data to estimate the mean dynamic topography of the North Atlantic and improve the geoid, Ann. Geophysic., 16, 638-650, 1998

Lemoine, F.G., et al., The development of the joint NASA GSFC and the National Imagery and Mapping Agency (NIMA) geopotential model EGM96, NASA Tech. Publ. 1998-206861, 1998.

Le Provost, $C$, and F. Ponchaut, Impact of the GOCE mission for ocean circulation study, final report, ESTEC contract 13175/98/NL/GD, Eur. Space Res. And Technol. Cent., Noordwijk, Netherlands 1999.

Mercier, H., M. Ollitrault, and P.-Y. Le Traon, An inverse model of the North Atlantic general circulation using Lagrangian float data, J. Phys. Oceanogr., 23, 689-715, 1993.
Nerem, R.S., et al., Gravity model development for TOPEX/Poseidon: Joint gravity models I and 2, J. Geophys. Res., 99, 24,421-24,447. 1994

Nowlin, W.D., Jr., and J.M. Klinck, The physics of the Antarctic Circumpolar Current, Rev. Geophys., 24, 469-491, 1986.

Reymaud, T., P. LeGrand, H. Mercier, and B. Barnier, A new analysis of hydrographic data in the Atlantic and its application to an inverse modeling study, Int. WOCE Newslett., 32, 29-31, 1998.

Rintoul, S.R., South Allantic interbasin exchange, J. Geophys. Res., $96,2675-2692,1991$

Saunders, P.M., and B.A. King, Ocennic fluxes on the WOCE A.1 section, I. Phys. Oceanogr., 25, 1942-1958, 1995.

Space Research Organization of the Netherlands, Institute for Astronomical and Physical Geodesy, and Delft Institute for Earthoriented Space Research (SID), GOCE End to End Performance Analysis, ESTEC Contract No. 12735/98/NL/GD, final teport 2000 .

Speich, S., B. Blanke, and G. Madec, Warm and cold water routes of an OGCM thermohaline conveyor belt, Geophys. Res. Lett., 28 , $311-314,2001$

Trenberth, K.E., J.G. Olson, and W.G. Large, A global ocean wind stress climatology based on ECMWF analyses, NCAR Tech. Note $338+S T R, 93$ pp., Nat. Cent. for Atmos. Res., Boulder, Colo., 1989.

Wahr, J., M. Molenar, and F. Bryan, Time variability of the Earth's gravity field: hydrological and oceanic effects and their possible detection using GRACE, J. Geophys. Res., 103, 30,205-30,229, 1998.

P. LeGrand, Laboratoire de Physique des Oceans, IFREMER, Centre de Brest, Boite Postale 70, F-29280, Plouzane, France. (plegrand(a ifremer.fr.)

(Received July 18, 2000; revised April 20, 2001; accepted April 26, 2001.) 